\title{
Confidence, Capacity Building and Cash: Achieving Sustained Impact for Ultra-poor Women*
}

\author{
Kassie Mcllvaine, Corey Oser, Julianna Lindsey and Maia Blume
}

\begin{abstract}
Understanding poverty and how to measure and eradicate it has evolved over the last 20 years to incorporate a multidimensional focus. The experience of Women for Women International (UfWI), a USbased non-profit organisation that works with women survivors of war in eight countries, shows that while economic inputs are crucial for moving above the US\$1.25/day poverty line, a more holistic approach is needed for ultra-poor women in conflict-affected situations to achieve this goal. This article analyses WfWl's 12-month social protection training and cash transfer programme for ultra-poor labour-constrained women in Rwanda and the Democratic Republic of Congo. The programme helps women obtain skills and resources to graduate from poverty and promote overall wellbeing for their families and communities. We first provide background on social protection programmes in conflict settings, then outline data collection methodology and the WfWl core programme, and lastly, we discuss our findings and opportunities for further analysis.
\end{abstract}

\section{Introduction}

Understanding poverty, how to measure it and how to eradicate it, has evolved over the last 20 years. During the last decade, experts have incorporated multidimensional definitions and indicators into programme design; however, most of these indicators remain focused on quantitatively verifiable improvements in income, assets, education outcomes, access to clean water and health care, and so on. Social protection programmes, many of which take the form of conditional and unconditional cash transfers, have focused on using economic inputs as an incentive to alter social behaviour or to achieve economic and social outcomes.

Women for Women International's (WfWI) experience indicates that, while economic inputs are critical to moving people above the US $\$ 1.25 /$ day poverty line, they are not sufficient for many ultra-poor women in conflict-affected situations to achieve this goal. Moreover, many poor women cannot take advantage of such economic inputs because they lack voice and agency, and because weak institutional capacity and ongoing violence present obstacles to implementing social protection programmes.
Without self-confidence and social networks, ultra-poor women in conflict-affected societies are less likely to graduate from poverty.

Reinforcing informal and grassroots networks in these contexts is an important strategy.

WfWI provides a 12-month social protection training and cash transfer programme for ultrapoor labour-constrained women in eight conflictaffected countries, including Rwanda and the eastern Democratic Republic of Congo (DRG). The programme helps women obtain the tools, skills and resources to graduate from poverty and achieve four outcomes: earn and save money; develop health and wellbeing; influence decisions in the home and community; and connect to networks for support and advocacy. WfWI thus defines graduation as achieving one economic and three social outcomes, as measured by eight programme targets aimed at achieving a sustainable livelihood.

The organisation's year-long, integrated vocational, business, and life skills training programme tackles issues related to the four outcomes for groups of 25 women. Participants receive a cash transfer of US $\$ 10$ per month for 
one year, conditional upon regular participation in training, as well as links to savings opportunities, microcredit and health services through partner institutions. Since its founding in 1993, WfWI has served more than 400,000 socially excluded, ultra-poor women and distributed more than US\$110 million in cash stipends and microcredit in support of women's economic and social advancement.

This article first discusses WfWI's programme in the context of social protection, with a focus on the implications for conflict-affected settings. Next, the article presents WfWI's definition of graduation, followed by the data collection methodology, intervention and findings. In conclusion, we address limitations of this study and highlight areas for future research and policy development.

\section{Social protection, graduation and conflict}

WfWI's programme fits within a social protection framework as it aims to reduce vulnerability, build capabilities to sustain a livelihood and ultimately improve status through active membership in family and communal life.

Positioned within Devereux and SabatesWheeler's (2004) transformative social protection framework, WfWI's programme model aims to:

- Protect against extreme deprivation through cash transfers and solidarity among women;

- Prevent adverse effects of future shocks by encouraging savings, building skills and networks;

- Promote increased capacity and knowledge through training in small business management, health, numeracy, agribusiness and other areas; and

- Transform women's perceptions of themselves from victims to active citizens through increasing understanding of rights, promoting group action and by assisting women to sustain increased earnings to enable them to emerge from the deepest level of income poverty.

However, the conflict-effected environments where WfWI works bring additional complications. Non-governmental organisations (NGOs) fill in the gaps where vulnerability of the extreme poor is high and governments usually do not have the capacity to deliver services (Carpenter, Slater and Mallett 2012). While the government in Rwanda has made substantial progress in service provision, in the DRC the informal sector, NGOs, civil society and grassroots networks play a critical role. WfWI's programme therefore focuses on both social and economic dimensions of sustaining a livelihood. In this context, WfWI aims to reduce women's overall vulnerability by increasing their financial security and enabling them to build confidence and self-esteem, understand their rights, connect with other women and become more active in their communities (Browne 2013).

WfWI's experience reveals that factors such as confidence and social capital developed through peer connections and participation in community groups are important prerequisites for graduation. As the CGAP-Ford Foundation Graduation Programme concludes: 'The socially excluded lack in self-confidence or opportunity to build skills and resilience needed to plan their own future' and 'indicators of hope, selfconfidence and orientation toward the future may be key' (Hashemi and de Montesquiou 2014). Browne concurs, noting a 'consensus across the literature' that much of the long-term success after exiting from a programme depends on 'confidence, empowerment, social networks and skill' (Browne 2013). WfWI's programme is structured to foster this resilience by creating space for bonds to form among women during the programme cycle.

Evidence from women's programming led by other organisations supports this view. The Women's Income Generating Support (WINGS) programme in conflict-effected northern Uganda tracked increases in cash income, assets, consumption and savings among the poor women it served (Blattman et al. 2013). The intervention included four days of business skills training, a start-up grant of about US\$150, and regular follow-up by community workers. Group formation, training and spousal inclusion were optional. Evaluation found no gains in health or empowerment and almost no effect on noneconomic indicators (ibid.). Recent research on additional interventions also shows that a combination of a 'very large' asset transfer and intensive vocational training combined with life skills can significantly impact young women's employment and earnings but does not effect non-economic gains (Bandiera et al. 2014). 
3 WfWl's definition of graduation from poverty

WfWI defines graduation as achieving one economic and three social outcomes, as measured by the following eight programme targets aimed at achieving a sustained livelihood.

\section{Income}

- 75 per cent of women we serve earn $\mathrm{US} \$ 1.25 /$ day;

- 80 per cent of women we serve utilise financial products.

\section{Health}

- 50 per cent of women we serve utilise at least one form of reproductive health service;

- 50 per cent of women we serve eat nutritious food.

\section{Empowerment}

- 95 per cent of women we serve contribute to household decision-making;

- 95 per cent of women we serve share knowledge of rights with other women;

- 90 per cent of girls under the care of women we serve attend school.

\section{Networking}

- One hundred women's associations are networked to share knowledge, tools, skills and solidarity.

We are therefore not focused on graduation from our social protection programme, but rather on graduation from poverty broadly defined, i.e. whether a woman's life is improving. This multidimensional understanding of poverty is still being refined; in the coming years, we aim to tailor the targets to individual country contexts, as the minimum standard of living varies immensely between eastern Congo, Kosovo or Iraq. This tailored approach will be most relevant for the economic and health targets.

To strengthen the understanding of how to help women graduate out of poverty and how to measure their graduation, WfWI intends to re-examine our eight programme targets. Instead of focusing rigidly on the US $\$ 1.25 /$ day poverty line, which is more applicable to eastern Congo than to Kosovo or Iraq, we aim to identify a set of characteristics, perhaps related to assets or consumption, that correspond to the poverty line in each country. We will then measure whether women and their families achieve these characteristics within two years of completing their 12-month training. We will also consider creating a composite measure that combines economic poverty measurements through consumption or assets with social indicators related to health, decision-making, girls in school, and participation in social life.

\section{Methodology}

The data on WfWI's programme participants in the DRC and Rwanda discussed in this article are drawn from the organisation's internal data collection and analysis process. In order to monitor programme outcomes, WfWI's monitoring and evaluation (M\&E) system uses quantitative surveys that are administered at enrolment, upon programme completion and after 12 and 24 months post-completion. Analysing the impact of the programme 12 and 24 months after women complete training is critical to understanding whether gains are sustained and whether additional services need to be provided when progress begins to wane.

The surveys include questions on demographics, income, rights, health behaviours, children's education and community participation. When interpreting the results, inferences regarding the significance of correlation and causation should be avoided because, unfortunately, data have not been collected from control groups. In addition, statistical significance testing was not conducted; hence, the results are purely descriptive of changes observed over time.

The cohort of women analysed for this report was enrolled in WfWI's programme in 2009-10 and completed the programme in 2010-11. Staff collected one-year follow-up data on the same women in 2011-12, and two-year follow-up data in 2012-13. Additional data are mentioned for women who joined the programme in 2011 and completed training in 2012. Interviews were conducted with a small sample of former participants from various years and with programme managers from both countries.

This methodology does have limitations. No control group was analysed to determine whether success can be attributed to WfWI's work. An external, mixed method, randomised controlled trial would be needed to measure rigorously the success of all components of the WfWI programme. 
5 Programme participants in the DRC and Rwanda

There are myriad political and economic challenges in the DRC. Despite its vast

resources, it is one of the poorest countries in the world, and 71 per cent of its population live on less than US\$1.25 a day (World Bank 2013).

Sexual and gender-based violence are a defining characteristic of the conflict in eastern Congo, and with limited economic opportunities, women often feel forced into risky activities to cover their basic needs (Weijs, Hilhorst and Ferf 2012). Social protection services are primarily provided by NGOs, as government services, where available, are constrained by human resource and financial limitations and are often not concentrated in the areas of greatest need (World Bank 2013).

WfWI launched its programme in the DRC in 2004 and has since provided services to approximately 58,000 women. There are currently 11,214 women enrolled in the WfWI programme in the DRC. It operates three main training sites in Bukavu, Uvira and Goma in South and North Kivu provinces and an additional 17 satellite training centres within accessible radius of these locations. Typical programme participants have borne the effects of protracted conflict, including rape survivors, returnees and HIV-positive women. Most of the women are economically active in subsistence farming or petty trade when they join the programme. In 2013, 82 per cent of participants were between the ages of 18 and 40, while 81 per cent were married, 7 per cent were divorced or separated and 9 per cent were widowed. Twentyeight per cent of participants had attended primary school, while 61 per cent had no formal education and 65 per cent considered themselves unable to read and write. Participants had an average of four children under their care with 62 per cent and 63 per cent of age-eligible girls and boys in school respectively.

Poverty remains a persistent challenge in Rwanda, although a combination of government programmes and foreign aid has resulted in progress over the last decade. Nevertheless, 27 per cent of the population is living in extreme poverty (World Bank 2013). Income inequality is also relatively high compared to other countries in sub-Saharan Africa (World Bank Development Research Group 2014). The government's Poverty Reduction Strategy aims to reduce poverty and provide links to social protection programmes to 'enable graduation from extreme poverty' (Republic of Rwanda 2013). Specifically, the government has implemented the Vision 2020 Umurenge Programme (VUP), which, among other services, gives cash transfers to vulnerable households to help cushion them against devastating shocks.

WfWI has been active in Rwanda since 1997 with more than 36,000 women participating in the programme in 18 communities with training in Kayonza, Rwamagana, Gasabo, Kicukiro and Muhanga districts. There are currently 6,920 participants in the Rwanda programme. The women who are economically active at the start of the programme are typically subsistence farmers or petty traders. Out of participants enrolling in the programme in 2013, 76 per cent were between the ages of 18 and 40, while 71 per cent were married, 4 per cent were divorced or separated and 12 per cent were widowed. Sixtytwo per cent of participants had attended primary school, while 33 per cent had no formal education and 37 per cent were illiterate. Participants had an average of two children under their care with 72 per cent and 76 per cent of age-eligible girls and boys in school respectively.

\section{Women for Women International's skill- building programme}

This section discusses WfWI's holistic programme of cash transfer, life skills, business and vocational training, and linkages to complementary services. Coincidentally, WfWI's programme is similar to BRAC's Graduation Model programme. The primary differences lie in the 12 versus 18-24 month duration of the programmes, the group training approach versus home visits, and WfWI's emphasis on social empowerment for women.

\subsection{Women's training groups}

Before opening operations in a particular location, WfWI identifies groups of communities where there is a need for services, and targets socially excluded women through an assessment process. After enrolment, staff members organise eligible women into groups of approximately 25, typically from the same town or village, for lifeskills training. Although women do not select their fellow group members, they elect group leaders and meet every other week over the course of the year. The groups function as a source of mutual support, friendship and a safe 
space for sharing difficult issues, and as a network for business and community action.

The relationship between the facilitator and the women is also important. Facilitators are occasionally previous programme participants, but most have backgrounds in education, social work or rural development and a passion for connecting with women at the grassroots. They make periodic home visits to address the reasons for absences from training, offer support, build relationships with family members and assess outcomes.

\subsection{Cash transfer}

Each programme participant receives a modest monthly cash transfer of US $\$ 10$, conditional upon regular attendance in training sessions. In Rwanda, women are supported to open bank accounts and are able to receive their cash transfer through a bank by the third month of the programme. In the DRC, where financial institution coverage is much more limited, selected groups have been able to receive funds through microcredit providers but most receive the transfer in cash. WfWI is seeking ways to expand partnerships at a local level with the private sector to enable greater coverage of financial services. WfWI encourages participants to voluntarily save a portion of their cash transfer, and the importance of savings is discussed early in the curriculum. In the DRC and Rwanda, many women form or join savings circles.

WfWI links women in its programme with a 'sponsor', who serves as a source of emotional support and a connection to a larger community.

\subsection{Life skills}

The life-skills education component of the core programme is guided by a curriculum and toolkit for trainers: 'A Woman's World: A Training Gurriculum Guiding Women's Social, Economic, and Civic Participation toward Active Citizenship'. The sessions employ participatory methods, including case studies, role-play scenarios, group discussion and music and dance. The curriculum is divided into the following four modules.

\subsubsection{Sustaining an income}

After two introductory sessions to set the stage and build rapport among group members, this module discusses barriers to women's economic activity, including the value placed on women's work of all kinds, whether reproductive or productive. The module addresses the benefits of savings, building assets, credit, managing household finances, and livelihood opportunities in their communities.

\subsubsection{Health and wellness}

The second module introduces the concept of health as an essential human right and information on the prevention, treatment, and management of communicable diseases, nutrition, sexual and reproductive health, mental health and stress, hygiene and environmental health. The content is adapted to address health issues that are unique or especially pervasive in particular settings.

\subsubsection{Family and community decision-making}

Human rights are covered here, as well as the international, national and communal laws that affect women and what they can do as individuals and as a group to exercise their rights in their families and communities. In addition to rights, the module discusses the way decisions are made at the household and community level and practices negotiation skills and other strategies for increasing women's involvement in these processes.

\subsubsection{Social networks and safety nets}

The final topics explore the value of women's collaboration and how they can serve as resources for each other. Women's roles, groups and leadership at the community level are addressed with specific strategies for increasing activism. The curriculum concludes with a reinforcement of key messages throughout the year and an opportunity to reflect on each module, set goals and make personal and group plans for the future.

\subsection{Numeracy, business and vocational training}

The majority of participants from the DRC and Rwanda are numerate; for those who are not, 16 per cent and 23 per cent respectively, basic numeracy skills are a key foundation for their business activities. Training focuses on numbers, counting and simple arithmetic to attain a basic level of competency. Business training introduces participants to basic business concepts, including planning, selling, tracking expenses and income, and financing a business. Vocational training typically starts by the third month of the programme. 
Figure 1 Rwanda: women are decision-makers, 2009-12
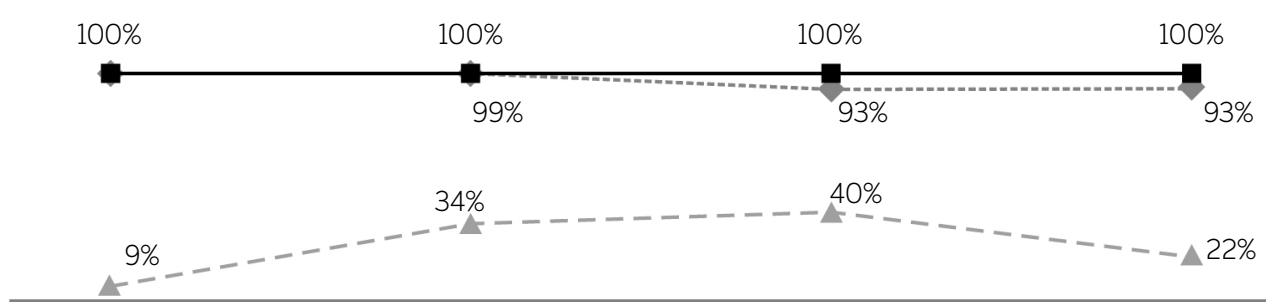

Enrolment

Graduation

1-year follow-up

2-year follow-up

-.-.... Involved in family planning decisions

$\longrightarrow$ Involved in household financial decisions

$-\rightarrow-$. Stopped violence committed against me

Source Women for Women International. ${ }^{1}$

\subsection{Service linkages}

In Rwanda, links to complementary services are an important part of enabling women to put the knowledge they have gained into action. A new partnership with a commercial bank provides training in financial literacy and credit products to complement women's savings accounts. An agreement with the Workforce Development Authority (WDA) will lead to a certification of WfWI's curriculum and training. WfWI also connects women to health centres and in some cases to employers. Women are encouraged to take advantage of protection strategies including insurance, legal marriage and birth registration for children. In the DRC, linkages provide medical and psychosocial services, especially for gender-based violence survivors, literacy training, and credit and savings, although the reach of these services is limited. Additionally, WfWI is engaging SENASEM, the government authority that provides quality control over seed production and regulates seed distribution to provide certification, which would allow the women to be registered on a list of certified vendors. WfWI is finalising an agreement with HarvestPlus to purchase seeds.

\section{Findings}

\section{Confidence to stop violence}

WfWI believes that freedom from violence helps to foster the psychological and physical wellbeing that facilitates sustained gains from social protection interventions. In Rwanda, the percentage of women who reported having stopped violence committed against them increased from 9 per cent at enrolment to 40 per cent 12 months after completing the training, but dipped significantly at 24 months postcompletion to 22 per cent (Figure 1). Staff believe that women do not realise they are survivors of violence when they enrol in the programme and gradually begin to address it after completion, resulting in an eventual reduction in violence:

After one year, they realise that they have been abused. They talk to their husbands. The reduction is linked to how they bring their husbands on board and sometimes you see violence because the women do not yet know how to put forward the argument about why they should not be abused (staff interview, March 2014).

One former participant experienced regular violence and was refused permission to attend WfWI trainings, which she attended anyway.

One time when I reached home after the workshop, my husband slapped me and I responded by telling him not to dare touch me again. I went to the local authority and reported him. He was summoned by the local authority. When he tried to resume the hitting again I reported him, and he was put in prison for a week and was released a changed man (pers. comm., March 2014).

Another former participant explained that she had dropped out of previous training courses because she was ashamed to appear with bruises from her husband's beatings. However, after learning about her rights and gaining confidence to combat the physical abuse, she was able to complete a vocational training course and is now earning a basic livelihood. 

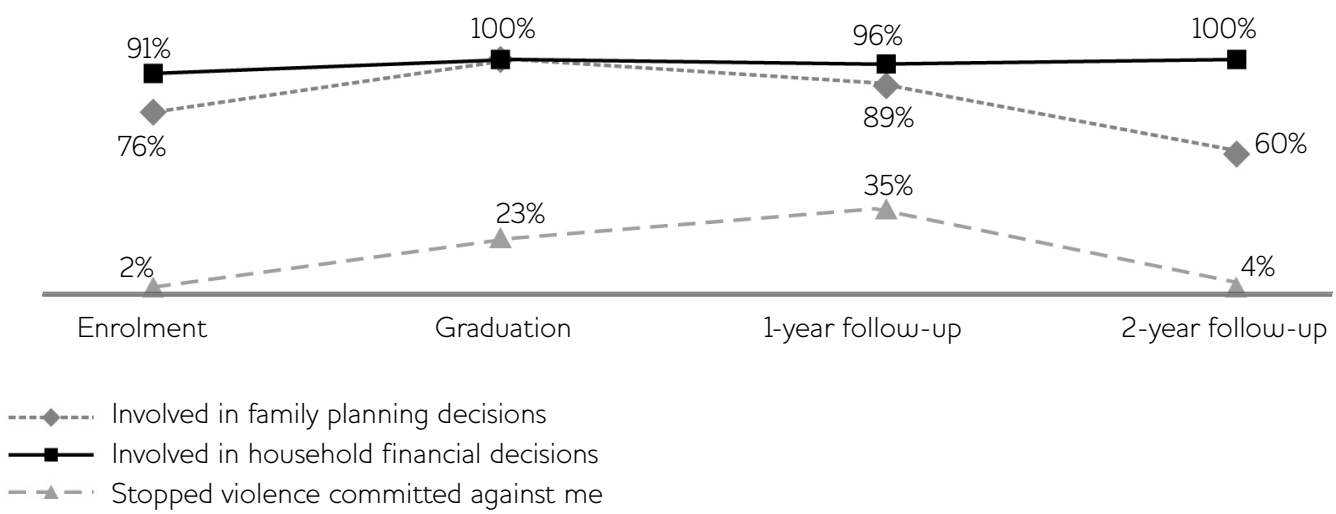

Source Women for Women International.

Similar to the case in Rwanda, only 2 per cent of women report stopping violence against them at the beginning of their training programme in the DRC. 'At the beginning of the programme, few women know what violence is' (staff interview, 27 March 2014). As women become more aware, this increases to 23 per cent at programme completion and 35 per cent at 12 months' post-completion, decreasing to 4 per cent 24 months later (Figure 2). While more research is needed to determine the causes for the decline between years one and two, staff believe that women may experience violence such as that perpetrated by armed groups, which they cannot stop by themselves, and NGOs may have moved to new areas, taking with them the key supportive structures.

\section{Decision-making and relationships with men}

Men's support for women and improved gender relations also contribute to women's ability to sustain changes and advance. Women report that they can express themselves better after the programme, leading to improved relationships with their partners and less violence in the home: 'Before I would get angry for every contradiction or different opinion with my husband, but now I take time to calmly discuss with him interesting topics about the household' (participant interview, March 2014). In order to address gender dynamics at the household and community levels and reinforce key outcomes of the women's programming, WfWI partnered with Brazilian NGO, Promundo, to pilot a programme addressing gender roles, sexual and reproductive health and domestic violence. Staff have found that engaging men increases the effectiveness of the women's training.
DRC staff note further community-level shifts after the men's training:

The community itself is sensitised in the places where men are trained. There is a difference between the communities where this intervention took place and where it didn't. Husbands and wives are now discussing priorities of their household. When men and wives are working together in the business area women were trained in, these are the households making progress, even the children. The whole family is working together (staff interview, 21 March 2014).

In some communities, men have started to become more active at home and are able to encourage other men by describing the increased harmony in their households. Staff believe there is great potential to expand this training for men.

\section{Income and savings}

The ability to sustain an increase in income is a key indicator of graduation out of extreme poverty. In Rwanda, women's average daily income follows an S-shaped curve, where income increased from US $\$ 0.32$ a day at enrolment to US $\$ 0.77$ a day at programme completion, only to fall to US $\$ 0.57$ a day at 12 months' postcompletion and US $\$ 0.60$ a day 24 months after the programme (Figure 3). Only a small proportion of women reported earning more than US\$1 a day, from 7 per cent at enrolment, to 20 per cent at programme completion, 15 per cent at 12 months post-programme, and 18 per cent 24 months after.

While programme participants nearly double their daily income between enrolment and two 


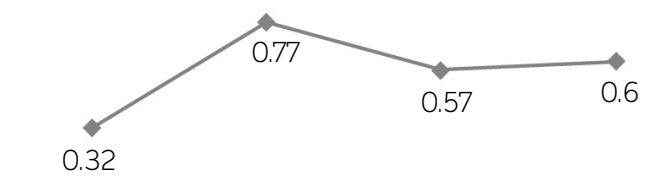

Enrolment Graduation $\begin{gathered}1 \text {-year } \\ \text { follow-up }\end{gathered} \begin{gathered}2 \text {-year } \\ \text { follow-up }\end{gathered}$

$\longrightarrow$ Average daily income

Source Women for Women International.

years after the programme, the overall level of income remains quite low. WfWI staff note that the market in Rwanda is becoming more competitive, with increased quality standards for both domestic and regional markets. Women who have received basic social and economic training in Rwanda require additional, more advanced, interventions to help increase their income gains, such as business start-up packages, wider access to suitable loan products and increased sensitisation about borrowing, business mentors, apprenticeships, and advanced entrepreneurship training.

WfWI's Rwanda staff recognise the government's support of the programme and general political will but believe that government can do even more with the large numbers of women who have completed the important 'stepping stone' programme:

District local leaders should seek the women and take them as a strong resource. When Women for Women leaves, they can call upon them. It is a group of people who have been given the basics. The local leadership should be able to follow up on them and identify opportunities. Sometimes for doing specific types of projects and also for further capacity building (staff interview, 21 March 2014).

Linkages to markets are identified as a particular area of need, as well as more coordination with the government to share data.

Savings is a critical indicator of resilience and ability to sustain positive economic changes. In Rwanda, savings shows a significant jump from 18 per cent at enrolment, 100 per cent at programme completion and 94 per cent and 97 per cent one and two years later (Figure 4). In the DRG, savings increased steadily during and
Figure 4 Rwanda: women sustain an income, 2009-12

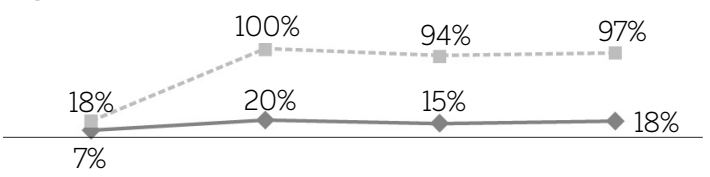

\begin{tabular}{|c|c|c|c|}
\hline Enrolment & Graduation & $\begin{array}{l}\text { 1-year } \\
\text { follow-up }\end{array}$ & $\begin{array}{l}\text { 2-year } \\
\text { follow-up }\end{array}$ \\
\hline \multicolumn{4}{|c|}{$\begin{array}{l}\longrightarrow \text { Earning more than } \$ 1 \text { per day } \\
\text { Saving money }\end{array}$} \\
\hline \multicolumn{4}{|c|}{ Source Women for Women International. } \\
\hline
\end{tabular}

after participation in the WfWI programme, from 5 per cent at enrolment to 64 per cent at programme completion, 95 per cent one year later and finally 97 per cent after two years (Figure 5). Income, however, takes a slight dip after leaving the programme for a few reasons, including the loss of investment capital after the cash transfer ends and the initial difficulty in applying some of the learning from training. One participant reports: 'I sell coffee, but my revenue does not increase since I don't receive the stipend (cash transfer). I used the monthly US $\$ 10$ to reinforce my capital' (participant interview, March 2014). As time continues, women who are still active increase their expertise in business, improve their networks and add additional income streams.

While the increase in income is significant, the lack of reliable sources of credit and capital reduce women's potential to expand further. When corruption and poor governance destroy confidence in microfinance institutions (MFIs) or government institutions, women resort to informal networks such as Village Savings and Loan Associations (VSLAs). WfWI staff find many women with good business ideas who lack sufficient access to capital to grow their activities, due to the inaccessibility of key financial services. Even for those living in areas with MFIs, confidence runs low due to cases involving misuse of funds and loss of deposits. Several participants describe their need for finance, including one participant who sells banana wine and makes and sells soap with her business group: 'There is an increase in revenue, but more capital is needed to buy more bananas and produce more wine to increase revenue' (participant interview, March 2014). 
Figure 5 DRC: women sustain an income, 2009-12

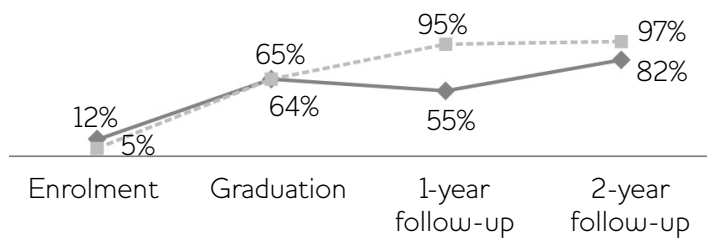

$\longrightarrow$ Earning more than $\$ 1$ per day

(-...-.... Saving money

Source Women for Women International.

Other barriers present challenges to women's economic advancement, including security.

Renewed conflict in an area can destroy women's livelihoods, forcing migration and abandonment of property. Staff believe there is also a need to re-enter communities where the programme worked previously to follow up on women's progress and provide further support to ensure that they are effectively linked to any existing services.

To further support women's advancement, deeper coordination with the government and the private sector, particularly in terms of links to markets, advanced training and financial services are important. Encouraging and reinforcing informal savings and loans groups and other networks formed by programme participants is likely to be more effective for promoting women's advancement, given government challenges and the limited private sector. Women's will to succeed through informal and grassroots networks, despite all obstacles, points to both the viability of these networks and even greater potential if there was stronger institutional capacity.

\section{Conclusion}

WfWI's social protection programme for women in the DRC and Rwanda is an important foundation to enable graduation out of the deepest levels of poverty. The data show that women have increased their incomes and savings, their health conditions, and their confidence in social situations. The women themselves repeatedly attribute their success firstly to their acquisition of voice and agency, and secondly to vocational and business training and the cash transfers. Women point out that the barriers to leaping above and remaining above the poverty line are not only economic, but rather that social challenges often prevent them from maintaining a secure livelihood.
WfWI has identified a number of steps to be taken to analyse rigorously the lessons from the stories that thousands of women have told staff members. First, the organisation aims to undertake an external, mixed method, randomised controlled trial to examine all aspects of the programme. In particular, examining change at the family and community levels will help to illustrate how success is multiplied beyond individual women. Second, a barrier analysis to women's advancement is needed to compare the characteristics of those who progress significantly after leaving the programme with those who do not, as well as an assessment of any declines in positive outcomes between the first and second year after the programme. Third, WfWI aims to find ways of measuring the marginal value of networks/social support in achieving economic outcomes, whether through formal self-help groups or cooperatives or through more informal social support systems. Learning from each of these projects should benefit not only WfWI programmes, but also social protection programmes run by governments and other NGOs.

Governments implementing and donors funding cash transfer programmes, business training programmes, and other programmes targeting marginalised groups need to include social empowerment components in their services. The return on investment of hundreds of millions of dollars spent on a cash transfer programme will likely be greater if the ultra-poor women receiving the cash are empowered to decide how to spend it. Similarly, women learning basic financial skills are more likely to hone the entrepreneurial spirit required to start and grow a business if they possess the confidence to take calculated risks and the assertiveness required to market their product.

Thousands of women join WfWI's programme each year isolated, unsure of their skills and the value of their contributions to their families and communities. Through sheer determination and their ability to join forces with each other, these women show that change is possible. Mobilising and building on women's potential through crosssectoral collaboration and reinforcement of informal networks is a critical step toward sustaining changes in the long term. 


\section{Note}

* Acknowledgements: Women for Women International (WfWI) is deeply grateful to the programme participants surveyed and interviewed for this study and inspired by their hope and resilience. WfWI recognises country programme managers for their contributions to this article. In the DRC, thanks to Gertrude Mudekereza with Celestin Pataule, Thomas Wilondja and Patrick Okoko Njakani and in

\section{References}

Bandiera, O.; Burgess, R.; Gulesci, S.; Rasul, I. and Sulaiman, M. (2014) Capital, Skills and the Economic Lives of the Poor: Recent Evidence from Field Experiments, CGAP-Ford Foundation Graduation Programme, http://graduation.cgap.org/wpcontent/uploads/2014/03/Capital-skills-andthe-economic-lives-of-the-poor.pdf (accessed 26 March 2014)

Blattman, C.; Green, E.; Annan, J. and Jamison, J. (2013) Building Women's Economic and Social Empowerment through Enterprise: An Experimental Assessment of the Women's Income Generating Support (WINGS) Programme in Uganda, New Haven CT: Innovations for Poverty Action

Browne, E. (2013) Post-graduation from Social Protection, GSDRC Helpdesk Research Report 1035, Birmingham: GSDRC, University of Birmingham

Carpenter, S.; Slater, R. and Mallett, R. (2012) Social Protection and Basic Services in Fragile and Conflict-affected Situations, Working Paper 8, London: Secure Livelihoods Research Consortium
Rwanda, thanks to Violet Kabarenzi, Clemence Bideri, Claude Muhizi, Donozius Byamukama, and the enumerators in both countries. Dr Su Chuen Foo designed the data collection methodology and conducted analysis with support from Molly Biel in Washington DC. WfWI is grateful to Bloomberg Philanthropies for financial support to implement these activities and research.

1 www.womenforwomen.org.uk/.

Devereux, S. and Sabates-Wheeler, R. (2004) Transformative Social Protection, IDS Working Paper 232, Brighton: IDS

Hashemi, S. and de Montesquiou, A. (2014) CGAP-Ford Foundation Graduation Programme, http://graduation.cgap.org/about/ (accessed 18 March 2014)

Republic of Rwanda (2013) Rwanda: Poverty Reduction Strategy Paper, IMF Country Report 13/360, Washington DC: International Monetary Fund

Weijs, B.; Hilhorst, D. and Ferf, A. (2012) Livelihoods, Basic Services and Social Protection in Democratic Republic of the Congo, London: Secure Livelihoods Research Consortium

World Bank (2013) Congo, Democratic Republic ofCountry Assistance Strategy for the Period FY2013-2016, Washington DC: World Bank

World Bank, Development Research Group (2014) Gini Index, http://data.worldbank.org/ indicator/SI.POV.GINI/countries?display $=$ map (accessed 8 April 2014) 